\title{
The Context of Globalization and Human Resource Need and Strategy for Developing Countries - The Case of African Countries
}

\author{
Philemon Kazimil Mzee \\ Additional information is available at the end of the chapter
}

http://dx.doi.org/10.5772/45615

\section{Introduction}

Globalization is a non-stop economic process; individuals, companies or governments are always on the lookout for new processes or innovations and so the economic and power structure of the world is never stagnant. It is clear that in creation of innovations not only technology is important, but also people, culture and communication, etc. Under going globalization process the necessity to investigate global human resource development and its differences from domestic human resource development appears. The main aim of this chapter is to explore the context of globalization on human resource development in developing countries the case of African countries. As we enter a new millennium, the effects of internationalization now known as globalization are everywhere apparent. This has played a major role in sustaining the economic expansion of the global economy in the second half of the $20^{\text {th }}$ century. Globalization is seemingly shrinking the planet as barriers to trade are dismantled, transport and communications costs fall, and global production systems are formed and managed by giant multinational corporations. Globalization can be defined as the ongoing economic, technological, social, and political integration of the world that began after the Second World War. There are several dimensions to this dynamic process, including the increased internationalization of economic markets, for example, in trade and financial capital flows. The rapid integration of the world economy through increased trade and investment, which has been fueled by new technologies, the spread of information and the growing importance of knowledge - based industries, provides the potential for opening up new avenues for human development. 


\section{HRM issues and challenges in global development}

\subsection{Overview}

The coming of the $21^{\text {st }}$ century globalization poses distinctive HRM challenges to businesses especially those operating across national boundaries as multinational or global enterprises. Global business is characterized by the free flow of human and financial resources especially in the developed economies of European Union (EU), the North American Free Trade Agreement (NAFTA), other regional groupings such as the Association of South East Asian Nations (ASEAN), the Economic Community of West African States (ECOWAS), the Southern African Development Community, (SADC) and East Africa (EA) respectively etc. These developments are opening up new markets in a way that has never been seen before. This accentuates the need to manage human resources effectively to gain competitive advantage in the global market place. To achieve this, organizations require an understanding of the factors that can determine the effectiveness of various HR practices and approaches. This is because countries differ along a number of dimensions that influence the attractiveness of Direct Foreign Investments in each country. These differences determine the economic viability of building an operation in a foreign country and they have a particularly strong impact on HRM in that operation. A number of factors that affect HRM in global markets are identified: (i) Culture (ii) Economic System (iii) Political System the legal framework and (iv) Human capital R.A. Noe, J. R. Hollenbeck. B. Gerhart, P. M. Wright, (2000) consistent with the scope of human capital (the skills, capabilities or competencies of the workforce). This is in consonance with the believe that competency based human resource plans provide a source for gaining competitive advantage and for countries profoundly affect a foreign country's desire to locate or enter that country's market R.A. Noe, J. R. Hollenbeck. B. Gerhart, P. M. Wright, (2000). This partly is why Japan and US locate and enter the local markets in South East Asia and Mexico respectively. In the case of developing countries, globalization poses distinct challenges to governments, the private sector and organized labor. These challenges, which must be addressed through a strategic approach to human resource management, include (i) Partnership in economic recovery especially in South East Asia (ii) Concerns over possibility of fraud in E-commerce (such as issues of confidence and trust) and (iii) Implementing prescriptions for recovery and growth taking in to consideration the development agenda and unique circumstances of individual country.

\subsection{The global trends of public administration transformation}

The first trend relates to the construction or re -construction of a State that operates according to the rule of law. There are a number of countries across the world undergoing a process of State construction or re - construction. Within this trend, we may distinguish two different movements. The first one that characterizes countries that need to build from scratch or re - build their government institutions, as is the case of some African countries, which have experienced war and internal conflict resulting in State collapse for example South Sudan, Libya, Egypt, ect. The second one relates to countries that have embarked in a process of political and economic change. This is, for example, the case of the countries of Eastern Europe 
who had to cope with a difficult transition from centrally planned economies to market economies. The challenge in this case is to dismantle old State institutions (or deinstitutionalize) and to bring them in line with new values of openness, participation, and transparency. The second trend relates to the modernization of the State. This is a challenge that affects all countries and is related to the adaptation and improvement of administrative structures, managerial capacities, financial management and technological adequacy to new needs and demands emerging from societies which are much more complex and heterogeneous than a few decades ago. In other words, it is a process of re-adjustment of State institutions and public management to the need for greater cost-effectiveness, quality, simplicity and participation in government. The need to enhance efficiency in the public sector and to cut public costs, which is at the heart of the New Public Management school of thought, has resulted in a series of measures, including privatization, deregulation, and the introduction of market like mechanisms in the public sector. In a number of countries, debureaucratization and decentralization have been increasingly coupled with new approaches to management, exemplifying openness, adaptability, participation, flexibility, diversity and responsiveness.

The third trend has to do with the reconfiguration of the role of the State. With the spread of globalization and the changes occurring at both the domestic and international levels, the functions and role of the State have been transformed substantially. The worldwide trends of globalization and citizen participation have compelled Governments to debate "the role of the State", to explore various partnerships with private sector and civil society organizations and to consider reengineering of government systems, retraining of public officials and rethinking of public policies. Given the rapid changes in technology and the global economy, Governments have also been motivated to learn to continuously reevaluate government performance in relation to citizen demands and global pressures.

The general configuration of State responsibilities has changed and this has introduced important modifications both in the policy arena and in the State's requirements for high level skills, qualitatively and quantitatively. Overall, the course of change points to a shift of focus away from hands on management and the direct production of services and goods towards strategic planning with a view to the establishment and maintenance, refinement and reform of an enabling framework for private enterprise and individual initiative. A parallel shift has moved the State's centre of gravity and with it the locus of power. Decentralization, de-bureaucratization and deregulation are adding to the importance not only of local government, but also of non-state actors on whom significant functions are devolved or outsourced. At the same time, a range of tasks and policy decisions, traditionally handled by national bureaucracies in their respective capitals, is being increasingly transposed to an inter-governmental or supranational level as a result of increased flows between countries of goods, capital, labour and information. Also, the State is called upon to act as "linking pin" of processes of planning, consultation, negotiation and decision-making involving diverse actors, State and non-state, at different levels of governance. The State is the hub of activities connecting multiple partners and stakeholders from very varied fields, regions, cultures, occupations, professions and interests. 
A fourth trend, which has emerged in the past years, is related to a growing demand to make democracy more meaningful and to allow for more opportunities of participation in policy-making. In many advanced democracies, citizens and civil society organizations are showing increasing dissatisfaction towards how democracies are functioning. For example, the growing influence of money in the electoral process and the strong influence of special interests on public policy decision making are being viewed in many democratic nations as undermining full citizens' participation. As a result, citizens are asking that government be reformed in order to enhance public participation, to expand political opportunities, and to improve its operations as well as the quality of services provided. In some parts of the world, the difficulty of governments to deliver adequate services, especially in the social sphere, and promote better living conditions for all has also resulted in a widespread disappointment among the population for the current forms of governance.

\subsection{The demand for transparency, participatory and efficient government}

One of the greatest challenges of our times is therefore to have not only governments of the people and by the people, but also for the people. This means greater participation in key spheres of policy making decisions, including how taxes should be spent and on what, and better and more effective services. Citizens are asking to be more actively involved in public affairs and to be engaged in many other ways than just at election day every four or five years.

As highlighted in the United Nations Millennium Declaration, the promotion of democracy and good governance, including an efficient and effective public administration, is among the best ways to ensure that the values of freedom, equality, solidarity, environmental protection, and shared responsibility are respected. Democracy and good governance are a goal in itself because of the values on which they rest, but at the same time, they are also the most critical means to achieve the United Nations Millennium Development Goals, which set very precise objectives, targets and indicators to achieve the broader goal set out in the Millennium Declaration related to development and poverty eradication. In fact, although many studies have not been able to show that democracy will lead to greater economic growth, there is evidence that democracy ensures greater redistribution of resources. One of the consequences of democracy is that it generates political incentives for decision makers to respond positively to the needs and demands of society. The stronger a democracy is the greater and more effective will be the pressure of these incentives on the decision makers.

Having in place a democratic system, however, is not sufficient. Government institutions need to be based on clear and widely accepted rules; to have committed leaders and qualified people to undertake appropriate reforms in the economic and social spheres; to be able to mobilize resources and manage expenditure; and to operate in the most cost effective way possible by making use of new information technologies. In other words, the legitimacy of a democratic regime is based in great part on the capacity of the State to deliver services that are relevant and of high quality to all sectors of the population in a society. The 
performance of the public sector depends on well functioning institutional structures as much as on the quality of the people who work in them. Skilled, dedicated and highly motivated public servants are essential for carrying out reforms that are effective and sustainable in the long term, as well as responsive to the changes that are occurring both at the local and global levels.

The essence of what the public sector is and its guiding principles (rule of law, serving the citizens, etc.) will shape its choices of how to solve the many challengesit confronts. Connecting the mission of the public sector with empowered public officials and a system that supports innovation and excellence can make a big difference in the future performance of the public sector. Human resources development is also a critical factor in ensuring that the development goals outlined in the road map towards the implementation of the United Nations Millennium Declaration are effectively achieved. Building public sector human capacities in terms of knowledge, skills, motivation and commitment, networks and mastery of information technology is crucial in order to be able to translate the values, objectives, and goals of the Millennium Declaration into nationally owned policies, strategies and action.

\subsection{Challenges and trends in human capital management}

The last 20 years have been difficult for the public service. We have seen too many reforms leading to too few results, too much rhetoric, too many keepers of single truth, and not enough wise leaders. Over the last 20 years, new forces such as globalization, information technologies, and innovation have transformed the way we think about governance, the role of government and the work done by public sector institutions. Both developed and developing countries have undertaken wide ranging reforms. Some have been remarkably successful; others not. We have seen progress on many fronts in different parts of the world, and we have also made enough mistakes that it should now be possible to look back and assess the lessons learned, as we turn our attention to the challenges ahead. Some resounding reform successes are worth noting:

- The construction and expansion of the European Union is one of the greatest achievements of our time in building a governance system based on progressive economic integration, democratic principles and human solidarity;

- The transition from an apartheid regime to a democratic society that guarantees equal rights to all citizens in South Africa has given hope to many who are leading ambitious reforms; and

- The successful transition from centrally planned economies to market economies in countries such as Slovakia, Hungary, Poland, etc. is showing the way to others.

We have also seen the consequences of the failure to provide for good governance. Many countries are still lacking:

- Political institutions to arbitrate conflicting views and to bring about peaceful resolutions of conflicts, 
- Democratic accountability and transparency in the exercise of power and the use of public funds,

- Political oversight of public sector institutions;

- Independent judiciary, and

- Law making and law enforcement capacities.

Serious mistakes were also made in some of the most prosperous countries of the world. For a time, it seemed that parts of the world lost sight of the importance of the role of the State as many decided to put their faith in the market's unlimited ability to resolve problems. This view transformed the role of government in many countries, with policies advocating a lesser role for the state and a greater reliance on market forces.

As a consequence, a high price was paid in many countries. It damaged the sense of pride of the men and women who had dedicated their life to the public service and convinced a number of young people to make a different career choice. Despite the diversity of governance experiences in the context of the rapid and deep societal changes of the last 20 years, we are facing many common challenges. We must all explore how the public sector can work best and bring value added to society in the future. It has become customary to talk of:

- The transformation brought about by the forces of globalization,

- The impact of information and communication technologies and

- $\quad$ The emergence of knowledge based economies and societies.

The author will not except obliquely, address these issues as they all have been covered previously. This chapter will try to provide a general context to this theme by looking at broad challenges and going back to the meanings of some core principles that tend to take for granted. In order to "Unleash the Human Potential for Public Sector Performance" we should first ask ourselves for what purpose? What will be the role of the State in the future? How can we unleash the potential of the State and of Public Sector Institutions to ensure a high standard of living and quality of life, to promote social justice and to provide for the peaceful enjoyment of life? This chapter frames this overview by discussing three challenges: finding the right balance between the market and the State in a global context, the need for leadership within the civil service, and the impact of the knowledge imperative.

\subsubsection{A search for balance}

One of the great lessons learned over the last 20 years should be the need for balance between the role of the markets and the role of the State. Each one makes a unique contribution. Each one operates in accordance with its own set of values, and each one is deserving of respect in its own right. The market is the most efficient way to allocate scarce resources and to ensure the pursuit of individual interests. The State (and in particular democratic State) is the most efficient way to ensure social cohesion and the pursuit of collective interests.

The first supports market choices, the latter collective values. One encourages individual choices and contractual arrangement, the other political consensus and covenant. One seeks to maximize individual benefits, whereas the other protects individual rights and the rule of law. One encourages competition, the other collaboration. 
For a well performing economy and society to flourish, it is not about the dominance of one over the other, it is about a search for balance. Both are fallible, both have inherent weaknesses, but by working together, they compensate for each other and achieve the best results. The lack of balance between the role of markets and the role of the State is partly responsible for several significant failures in public sector reforms:

- The Asian crisis in 1997 was not caused by "excessive" regulations but rather by the absence of an adequate regulatory framework;

- Some countries like Korea, Thailand, Argentina and Indonesia were encouraged to cut their deficits by reducing the role of the State and cutting taxes at the worst possible time in their economic cycle, which in turn magnified the crisis;

- There is no direct evidence that tax cuts have helped to create wealth and employment but rather an indication that they led to higher deficits and increased economic disparities between the wealthiest and the poorest in the countries that followed this prescription prematurely; and finally

- Russia is the most compelling example of the need to build the State in order for the market economy to flourish. The call for "less government", without the appropriate regulatory safeguards was, to say the least, ill-advised.

To unleash the human potential of the public sector, we must first articulate in modern and compelling terms the importance of the role of the State and of public service institutions. This is the first, and perhaps the most difficult challenge.

Achieving balance will require political leadership to state the importance of the political processes and the role of public service institutions in meeting new and emerging needs. It will require leadership within the professional public service to bring about the changes needed to serve the collective interest.

Reaffirming the need for balance, and restating the importance of Government in liberal market economies would do much to restore a sense of pride in a public service career and to rebuild a relationship of trust between citizens and public sector institutions. Choices about the role of Government in society have a direct impact on the ability to attract and retain talents in the public service, and to provide for stimulating employment and career development opportunities.

\subsection{2. "Physician Heal Thyself" (Luke 4: 23)}

In my opinion, the primary responsibility for reform in the public service rests with the public servants. Obviously, public servants should be able to count on the support of elected officials to bring about legislative changes to marshal reforms that affect the whole of government. But by and large, the public service should take responsibility for on-going reforms and bring about the necessary improvements in order to fulfill its mission. Too often, the public service hides behind a so-called lack of "political will" without demonstrating its own willingness to bring about changes.

The author is among of those who believe that "New Public Management" (NPM) has done as much harm as good, because: 
- It converts citizens into customers,

- It shifts the focus from the collective interest to user satisfaction,

- It borrows from private sector management practices without adapting them to public sector values and principles, and

- It erodes the professional public policy role by transferring it to the political level or to independent organizations.

That being said, the frustrations and the disenchantment of citizens with the public service, which led to NPM, are only too real. Citizens demand and deserve high quality service exempt from patronage or influence peddling. They expect access to information, and they expect services to be organized and delivered in accordance with their needs and circumstances, not at the convenience of departments or civil servants. They demand to be treated with respect by public sector institutions and public servants true to their mission of being the "servant" of the collective interest and the "keeper of a public trust".

The second challenge, therefore, is to accept the responsibility to bring about the changes within our power. The public service model, as we know it today in most countries, was inherited from the industrial age. It is the result of the work by Adam Smith, F.W. Taylor, and Max Weber. The Weberian concept of the Public Service in the 19th century:

- Advocates a clear separation of roles between political and professional functions;

- Is built around a hierarchical system of accountability to Ministers and Parliament;

- Operates an administrative regime based on the rule of law, the protection of citizen's right and due process; and

- Recognizes the need for a professional, competent and meritorious public service.

These basic principles remain valid today. However, Author strongly believes that we need to modernize their definition and their application. To illustrate this point, the author refers to the rule of law, the merit principle and the need for due process. Our commitment to these principles should never be used as:

- A pretext to prevent needed reforms,

- A justification to oppose the reform agenda of a rightfully-elected government, or

- As a means to defend corporatist interests.

Unlocking the human potential of the public service starts with facing the truth, no matter how uncomfortable this may be at times. Firm commitment is to leave the future generation with better institutions than the ones we inherited.

- The Rule of Law

The respect for the rule of law is one of the most fundamental principles of public sector institutions. Unfortunately, incidents related to the inability to eradicate corruption and take forceful action to address proven incidents of wrongdoing continue to undermine the credibility of the public service and public servants. This is not a matter of a Minister alone. Much can be done in the public service by public servants at all levels. 


\section{- The Merit Principle}

It is necessary to protect the public service from political interference in the recruitment and promotion processes, in order to build professional and highly competent institutions. The "merit principle" was never intended to grant immunity for poor performance. A commitment to the "merit principle" does not imply guaranteed promotion or guaranteed employment for life. While we need to defend and protect the "principle of a meritorious public service", we must also be prepared to review and change the "merit system" invented by the public service to give it effect. There is evidence that the "merit system" put in place in some of our countries did not always advance the merit principle but contributed instead to encouraging a corporatist approach and prevented much-needed reforms.

- $\quad$ Due Process

The commitment to due process is no justification for red tape, or inefficient and disjointed operations in Government. The public sector is not inherently less efficient than the private sector; more complex, yes, but not less efficient. Many of the policies, controls and procedures are not required to fulfill the requirements of the rule of law. They serve instead to satisfy the appetite for control and power by some, at the expense of the commitment to serving citizens.

These three core principles are sound but we need to revisit their definition and their application in order to ensure the ongoing relevance of the public service to citizens' needs and to remaining deserving of citizens' trust.

\subsubsection{The knowledge and innovation imperatives}

The other challenge is pertains to the "knowledge and innovation imperatives" that are in so many ways characteristic of the era we live in. The bureaucratic organizational model in the public sector and the industrial management model in the private sector have characterized the organization of work for most of the last century. They were built around clearly defined and predictable tasks. Similar tasks were grouped into units, units into branches, and branches into departments. The organization relied on a strict division of labour. The authority was delegated top down.

A profound transformation took shape in the private sector during the 70's, 80's and 90's as the knowledge-based economy started to take shape. When the assets of an organization become intellectual, the old management model starts to break down.

The public service has been slower to adapt, but it must, in order to provide value added, remain relevant to citizen's needs, and continue to be an attractive workplace. This transformation will be critical to the ability of the public service to attract and retain its fair share of the best talent in the future.

Let's look at this more carefully. The nature of work in the public service is shifting from tangible to intangible services (building a road vs. providing information), from mass 
production of the same service to citizen centred services (issuing checks vs. assisting startups).

The organization of the work is also changing and is increasingly dependent on the use of networks reaching inside and outside, well beyond the traditional boundaries of the organization. This requires new ways of thinking as there is a need to implement a "whole of government" approach, supported by horizontal management and team work, in order to effectively promote and respond to the broad range of public interests in a cohesive and coherent manner.

The structures of authority are changing. The power of the office must now co-exist with the power of ideas, the power to innovate, and the power to discover new and better ways to fulfill the mission. Training for a job, as it was done in the past, only works when the content of the work is predictable and repetitive. Learning, on the other hand, is central to the ability of an organization to innovate, and will be key to the future of the public service. At the practical level, this means preparing highly competent and qualified knowledge workers who will have the added characteristics of being learners, innovators and entrepreneurs.

It remains an open question whether, and to what extent, the public service will be able to adapt to the "knowledge imperative" and to encourage innovation. It is a complex undertaking and some countries will choose a more modest role for their public service. Innovation that fails in the private sector can damage a firm's reputation or affect shareholder's return. In the public sector, the consequences of failure are borne by citizens. A successful innovation in the public sector is largely invisible but a visible failure can put an end to a brilliant career. Securing innovation in the public sector represents a conundrum. On the one hand, creating a public and political constituency for innovation is a challenge: the tolerance for failure and even for reasonable risk-taking is low. The current public service management systems do not encourage innovation, favouring instead predictability in a given range of activities. On the other hand, failure to transform bureaucratic organizations into "intelligent" and "learning" organizations, able to explore and find new and better ways of achieving their mission, might signal their declining relevance in the future.

There can be no innovation without some degree of tolerance for failure and reasonable risk taking. The way the public service adapts to the "knowledge and innovation imperatives" will set the context for human resource management reforms in the future.

The competition for talent will be fierce among countries and between the private and public sectors. People will come to the public service if they are given the chance to make a difference, and the opportunity to use their skills and reach their full potential. A public service whose role is limited to repetitive and predictable tasks will attract a different kind of workforce.

The old "bargain" of lower compensation than the private sector, in return for greater job security, is no longer realistic. A reasonable pay, new skills and lifelong learning are key factors to a sense of personal security and employability. Today, one must learn a living to earn a living. 


\subsubsection{Globalization and migration}

Migration is defined as, "the temporary or permanent movement of persons between countries to pursue employment or education (or both) or to escape adverse political climates" I. Goldin, K. Reinert, (2007). These authors note that migration causes brain drain, which is the loss of educated and highly skilled citizens to other countries. In African countries we have lost very many well trained human resources in key positions to developed countries. They have been lured by better pay and working conditions as well as the promise of a better life. This 'skill poaching' by the developed countries has had detrimental effects in the production, community service sector, as well as in education at the higher levels. In the public universities the scenario is the same whereby key trained lecturers are moving to other countries with a lot of ease and many of those who go out for education opt to remain outside. The United Nations Population Division UNCTAD, (2003) produced the world migrant stock that showed the number of migrants had increased from $16,351,076$ in 1990 to $17,068,882$ in 2005 . High income countries use skilled migrants to fill occupational shortages that cannot be met by training resident nationals. Migrants take with them skills in critical demand. In African countries, we have lost a good number of well educated people who have migrated, which means the loss of leaders, innovators and household heads which has its own social and political costs. The social costs include the loss of social cohesion, dynamism and growth potential of the economy. A recent study of the Organization for Economic Cooperation and Development (OECD) suggests that "emigration of highly skilled workers may adversely affect small countries by preventing them from reaching a critical mass of human resources, which would be necessary to foster long-term economic development" OECD, (2004b). Emigration deprives governments of tax revenues, depleting the quality of public services and preventing society from earning a return on money invested in the education of migrants. In a report entitled Least Developed Countries (LDCs) LCD - UN report, (2007) economic growth and the creation of employment opportunities for educated manpower in LDCs appears to be closely associated with slower rates of brain drain. The report indicates that the reasons for brain drain are slow economic growth and political instability, especially in Africa. The low level of pay and the huge and widening gap between earnings in LDC's and those in developed countries are also to blame. M. Brown, J. B. Meyer, (1999) Report that 40,000 scientists and engineers from developing countries are employed in research and development in high income countries, compared with 1.5 million who are working in their home countries. About 70,000 professionals and university graduates are thought to leave Africa each year to take up work in Europe or North America T.L. Weiss, (2001).Therefore is clear from statistics that globalization has had own negative effects on the growth of labor pools in Africa countries and this would explain the reasons why they progress so slowly.

\subsubsection{The impact of HIVIAIDS on public human resource in Africa}

There continues to be global concern for the apparent relentless scourge of HIV/AIDS. In the last two decades the unleashing of the HIV/AIDS pandemic in Africa became yet another 
development challenge to a continent already plagued with a plethora of challenges into the twenty first century. The peculiar political and socio-economic landscape of Africa with its tribal based wars, dictatorships and poverty makes this all the more challenging. Africa is struggling to cope with the devastating impact of this pandemic on the functioning of its societies. There is an impending crisis projected in the macro economy of Africa. The AIDS/HIV pandemic also places heavy costs on business through increased medical aid claims, life and disability insurance, increased absenteeism due to ill health, funeral attendance or the need to care for the sick family members, loss of skilled workers and the increased cost of recruiting and training replacement workers, reduced job performance due to disability, etc HIV/AIDS Pandemic in Lesotho, (2003) p 206. It also impacts negatively on international competitiveness, deters domestic and foreign investment and is a potential threat to security in the region.

\subsubsection{The HIVIAIDS challenge}

The devastation that disease alone has caused on Africa is underrated. For instance, Malaria is seen as having impacted on Africa by slowing economic growth by between $1.3 \%$ and 2.6\% a year. Zuma: (2003) cited in IDASA UNDP 2003. This chapter presupposes that the challenge of HIV/AIDS in Africa can only be dealt with, if Africa internalizes HIV/AIDS as an infectious disease crisis, especially when it is on record as being the continent with the highest HIV/AIDS infections. In other words the HIV/AIDS problem has to be identified and defined as what it is and not on perceived and unfounded premise. In arguing for this as a foundation for interventions, it is observed that societal labels and views on diseases can affect the actions and outcomes in tackling some diseases Kevin De Cock et al: 2002, The Lancet p. 67. A case in point being the crusade of Thomas Parran, the US Surgeon General under President Roosevelt to demystify syphilis and address it as a public health problem rather than as a moral issue. Ibid

More than fifty years later, the emergence of HIV/AIDS, and the moral issues it raises have also raised the platform in terms of government engagement with the disease. Some authors argue that as yet some approaches to HIV/AIDS in Africa are poorly structured to the crisis because it has not yet been identified and dealt with as an infectious disease crisis. That is to say, the issue of prioritization is vital. This will involve political commitment, normalizing or mainstreaming HIV/AIDS into governance and leadership and government institutions, structures and systems.

Subsequent discussions will also deal with responses, which can be construed as indicative of the primacy of HIV/AIDS in governance and leadership consciousness.

This section has attempted to establish the need for reorientation of perceptions and the prioritizing of this pandemic as well as its integration into the very fabrics of nation building as a precursor to this discussion. Examining some micro and macro concerns will approach the challenges of HIV/AIDS in the African public service. First, an examination of Africa's peculiar challenges in confronting the pandemic will be looked at, and then the challenges in the micro environment of work place human resources will follow. There is little doubt as to the challenges that Africa faces in the present world milieu. 
This especially true as Africa has suffered more than others from not being integrated into the world economy. Not too long ago the international political and economic balance tended towards a dependency theorist tilt of Keynesian, Andress 2002:4; Amsden 2003:33 views of protectionist theories, harnessed by national subordination of poor countries and exploitation by rich nations. However, with the emergence of new economies of the East (Asian Tigers), models of regional integration for global relevance have begun to emerge. Growth triangles of ASEAN countries Ravenhill John (2001) have created state initiative and private entrepreneurship in countries like Malaysia, Indonesia and Singapore. These eastern trends have further set the pace for the internalization of the need for "collective self reliance" Laszlo Ervin, Krtzman Joel and Bhattacharya AK. (1981) these developments only go to mirror the image of the decrepitude of the African scenario. For instance NEPAD (2002) Annual report of the world's least developed countries are in Africa, the aggravation of poverty continues with about 300 million Africans living on less than US\$1 a day Ibid, p 3.

While there is a need for a global response to Africa's crisis developments such as wars, and the devastation of disease, it is premised in this discourse that despite global support and interventions, a total commitment to fighting Africa's problems can be best broached by Africans themselves. This is because, Africans are in the unique position to philosophically and ideally face problems given their own peculiar social and political environment. The HIV/AIDS crisis will therefore require an approach, where prioritization and ownership of the HIV/AIDS pandemic becomes a reality in Africa. This will however, not take away the genuine economic, social/cultural and political challenges that will always pose a barrier to progress in combating the HIV/AIDS pandemic. Some of these are unpackaged subsequently.

\subsubsection{The HIV/AID and human capital challenge}

HIV/AIDS is a development problem. The estimations of the impact of the pandemic in terms of its toll on human capital are adverse. The uniqueness of HIV/AIDS in terms of its main mode of transmission makes it more volatile than other diseases like Malaria and even the deadly Ebola virus. This deadly silent mode of transmission through sex as well as its long spanned incubation also exposes more people to the disease over time. For instance, it is estimated that in most affected countries, half of all 15 year olds alive will eventually die of the disease, even if infection rates go down in the next few years Abdoulie Janneh (2001)

The impact of HIV/AIDS from a human resource perspective has both policies as well as capacity challenges. Appropriate human resource strategies must be developed by human resource management components whilst human resource capacity in crucial areas of service delivery will have to be maintained.

The rising threat of HIV/AIDS on Africa's work force has been one of concern to government and employers of labor. In South Africa for instance it is estimated that about 5.3 million South Africans were HIV positive by the end of 2002, and increase from the comparable estimate of 4.74 million in 2001 AIDS policy research center: (2002). ILO fact sheets www.ilo.org/public surmises that in Malawi between the years 1990 and 2000, deaths among public service workers increased tenfold, as a result, unfilled vacancies in 
national ministries of education, health, agriculture and water development stand at over $50 \%$. There have been ideally a number of descriptive and explorative studies that have been done which give us a fair estimation on statistics on the socio-economic impact of HIV/AIDS in the work force due to ill health and death. There is no doubt as to the magnitude of the problem that faces Africa in terms of the pandemic, however, the problem that faces Africa will be the issue of how to engage with the pandemic, to mitigate the risks involved. A few issues deserve particular attention.

\subsubsection{Remarks}

Having traced the plethora of challenges that confront Africa, and having mapped out certain possible routes to engaging with the pandemic, it must be stressed that while none of these targets for engagement are new, what is emphatic in the approach of this chapter is to bring forward the issues of African ownership for the solution of its challenges and its peculiar environment. It should be acknowledged at this juncture that although the African continent has made strides towards tighter regional integration and self help, it is a long way from the beginnings of change.

In proposing a human resource response, this chapter focused closely on the Employee Assistance Programme (EAP) due to its unique reflection of the spirit of Africanness (Ubuntu), working together for change. Africans should not forget therefore their early thriving communities based on traditional values of brotherhood and enduring cultures incomparable to any in the world. This is one approach that will reduce stigma, as well as create a sense of ownership especially as Africa moves from the era of the infected to the affected.

This is not to say that core strategic thinking in curbing the tide of deaths and infections will not need a comprehensive approach, one that involves all sectors and all tangents of the disease. Moreover, while recognizing strategies that will mitigate the impact of HIV/AIDS in the workplace, a holistic picture for engagement indicates that poverty and food shortages, gender based discrimination imbedded in various

African indigenous cultures, as well as limited access to basic education are still some of the core challenges that will need ongoing interventions in Africa. Finally, the philosophical undertone of this conclusion is intended to place value alongside solutions. This means that while the search for solutions continues, where possible those African traditional values that define the African fighting spirit should be encouraged to rise above the fear and trepidation in any challenge. It is hoped that this chapter has served to stimulate African minds to the need to fully put our resources and our sense of oneness to deal with this pandemic.

\section{Human resource needs and strategies for development in Africa}

\subsection{Development and human resource in Africa}

What is the current state of staffing in terms of numbers, knowledge, skills, attitude, etc in the public service in African countries? To answer such a question one would need to 
undertake a comprehensive stock taking and analysis of public service employees in every country. The author cannot claim to have conducted such an extensive and laborious exercise. Reading through public/civil service reform documents in a number of African countries, it is evident that the public service has for long been experiencing difficulties in recruiting and retaining competent staff let alone talented ones. The situation may vary from country to country but it is generally acknowledged that recruiting and retaining professionally knowledgeable, skilled, committed, talented, and motivated personnel in the public service constitutes a daunting challenge in African countries. The worrying concern is that existing levels of talent in the public service in many countries in Africa cannot support and sustain the achievement of the development aspirations of the continent, let alone the globalizations challenge as well as Millennium Development Goals. Another worry may be expressed in terms of a question: Does the public service in Africa really aim at attracting the best talent? If yes, through what approaches and methodologies is this done and with what results? If the stock taking and analysis of the staffing in the public service arrives at the conclusion that existing levels of talent in the public service in many countries in Africa cannot support and sustain the achievement of the development aspirations of the continent. Where did the public service go wrong to have its attractiveness and capacity eroded and what can be done to reverse this process and address the situation? Where did it all begin? Where will it end? How can it end? If the public service must recruit and retain the best talent, what talent should be targeted? What are the talents (skills, knowledge, and attitudes) that are critical to the performance of the public service and through what approaches, methodologies and practices can such talents be identified, attracted, recruited, nurtured, developed, deployed and utilized? In the context of Africa where issues of poor governance are paramount on the table we need also to ask ourselves the question of to what extent the best talent can be utilized for optimum performance in the context of a poor governance environment. Is it realistic to expect the public service to attract the best personnel in the context of poor governance? What are the governance issues that must be addressed in order to provide a context that is conducive for the public service to be attractive and to recruit and retain the best?

\subsection{HR capacity building in the public sector}

Governments all over the world need to face the challenge of having in place adequate human resources in the public sector in order to plan, implement, monitor and evaluate policies and strategies for achieving the Millennium Development Goals, including poverty eradication. There is a general tendency to believe that the problem of inadequacy of human capacity in the public sector only affects developing countries. True, developing countries are being confronted with these serious problems; however, since in the context of globalization eradicating poverty in one corner of the world is equally a responsibility of all countries, developed countries also need to have the appropriate human capacity to understand, dialogue and negotiate with developing countries. If this capacity is lacking, then the job of poverty eradication becomes harder. In brief, a visionary and committed leadership as well as adequate human resources at the global, regional, national, and community levels are required to meet effectively the MDGs. 
At the national level, the quality of public sector human resources is crucial in enabling the State to provide leadership in defining a home-grown governance framework and national appropriation of the Millennium Development Goals. The State needs to provide leadership in this process through law-making, regulatory and security-related functions, as it is the ultimate guarantor of life, liberty and property.

Moreover, developing strong leadership and adequate human resources in the public sector is a crucial task in order for any country to prosper and undertake programmes that are aimed at reducing poverty. Finally, an effective public sector is essential in creating an enabling environment for private sector development and economic competitiveness.

Strengthening public sector human resources capacities is, however, not an easy task and many are the difficulties that need to overcome. Although all countries around the world are facing a number of challenges in modernizing their public sector, developing countries are facing even greater difficulties due to a number of factors, which include:

- The changing role of the State due to national and international factors;

- The erosion of public sector human resources capacity, and especially scarcity of effective public managers;

- The constraints in recruiting highly qualified personnel.

The reform of the public sector in developing countries has been greatly affected by constraints in recruiting high-quality personnel. The main factors that may describe this phenomenon are as follows: a loss of pride within and credibility outside the public service; brain drain to the private sector and to more economically advanced countries due to better salaries and career opportunities; and a gradual decay of national governance structures in stagnating countries. Human resources public sector reform has also been particularly difficult as the core competencies needed in the public sector have evolved and changed in a number of ways as a result of the changes taking place at the national and international levels.

Given this extremely complex situation, what the public sector needs more than ever is its fair share of the best talent in any given country to respond effectively to evolving traditional functions of the State, as well as the challenges of globalization and other social changes. Moreover, it is important to underline that improving human capacity in the public sector also requires sound public institutions and good governance. In other words, strengthening public sector capacity requires a holistic approach, which should begin by rebuilding trust in the public sector and promoting high-quality leadership. There are key issues that need to be addressed in order to promote adequate capacities among public servants, including:

- Reinforcing human resources planning and management systems and units;

- Reinforcing core public service values, such as:

- Revaluation of learning, integrity and competence;

- Low tolerance for corruption and crime;

- $\quad$ Stress on meritocracy;

- Growing sensitivity towards and respect for citizens' needs; 
- Fostering a political culture that places emphasis on the respect for institutions and norms over personal interest;

- Promoting professionalism in the public service;

- Creating a culture of learning organization;

- Introducing incentive structures, such as:

- Fair remuneration system; and

- Increasing recognition of the need to acknowledge and to reward industry, loyalty, accomplishment and merit;

- Increasing recognition of the value of cross-cultural and international links as means towards the improvement of the professional image and performance of the public service;

- $\quad$ Tapping the best talent from underrepresented groups, including women; and

- $\quad$ Promoting the knowledge and use of ICT tools.

\subsection{Effective leadership and good governance}

Fostering effective leadership is perhaps one of the most important and first steps to take in the reform of the public sector human resources. Effective leadership is critical to the future of governance, of democracy and of people's well-being. In particular, leadership enhancement programmes must be conceived and implemented with the aim of making leaders capable of effectively addressing the key issues facing the world today and the immense tasks required to meet the Millennium Development Goals. Leadership training needs to be interdisciplinary, international and inter-sectoral (involving public and nonprofit organizations). Leaders have to develop a cross-sectoral approach to solving problems and this is particularly critical to reducing poverty.

Taking into account the present political environment in an increasing globalizing world, new areas of leadership competency also need to be strengthened, in particular diversity management; knowledge management; horizontal management; resource and information management; partnerships and negotiation skills; communication and ICT skills. Leaders need to be able to deal with more ambiguity and in the face of difficulties and contradictions, including economic liberalism and social welfare; people getting poorer although they have more voice; and managing change while ensuring stability and security.

Given the diversity of administrative cultures and based on a variety of societal environments, each country leadership has to be open-minded and look at all the potential solutions to their own problems: the key element is to develop a sense of direction for the public service of a given country which takes into account its history, its environment and its position in the global world in a realistic manner.

In the process of public sector leadership capacity development, Management Development Institutes have a critical role to play. They constitute the infrastructure in their respective countries for management development; they have human resources capable of doing management research training and providing technical advisory and consultancy services in different aspects of management. In particular, they can play a leading role in training needs 
assessment, human resource policy design, personnel development programmes formulation, implementation, as well as monitoring and evaluation. On the one hand, they can assist governments in addressing the capacity needs of high-level government officials by focusing on strengthening expertise in strategic thinking and policy analysis, technical knowledge, and awareness of complex emerging issues. On the other hand, they can assist governments in reinforcing the capacities of civil servants who have to implement public policies by focusing on developing new skills, operational modalities, and techniques.

It is understood that some of these institutes, in fact most of them, will require to have their capacities reinforced, but this does not in any way minimize the role they are supposed to play. In particular, they can greatly contribute to the efforts being undertaken by many Governments in reaching the MDGs. In this respect, they should ensure that they have the appropriate capacity to assist Governments in this task by continuously upgrading their skills and techniques. These institutes may also play a very important role in promoting cooperation and sharing of information since they have networks at the national and regional levels through which they can pool expertise, facilitate exchange of successful practices and share innovative practices. In sum, building leadership capacities is one of the most challenging and urgent tasks that all countries face, and this in turn requires both good policies and institutions.

\subsection{Human resource need for development in Africa}

The following are the basic need to adapt:

- The critical human capacity needs for effective performance in the public service: Beyond numbers of public servants, human capacity refers to knowledge, skills, attitudes, networks and cherished values as well as institutions, systems structural arrangements as well as tools and logistics, are highly recommended.

- Strong and committed public service leadership at all levels: Capable of coping with the complexity and conflict contained in the context of globalization, and dealing with all forms of diversity including gender, race, and ethnicity.

- $\quad$ The knowledgeable, skilled and committed policy advisers: Given that governance and public administration includes the higher order tasks of providing policy advice and critical assistance in developing grand designs of society and nations, one of the primary roles of the public service is to ensure a capacity to develop policies and strategies, forecast and anticipate future trends, react to rapidly changing global and local conditions, be creative, challenge the status quo and be self critical,

- Human resource management professionals: In most public services in African countries, positions responsible for forecasting, planning, developing, and managing the human resources are occupied by individuals who are not professionally qualified to manage the human resource. Consequently the basics in personnel management, let alone human resource management are ignored. This is the case in personnel records, human resources data and information processing, human resources development including training, succession planning etc. The public service requires professionals capable of adequately supporting the human resource management function if the 
service has to develop strategies for attracting, recruiting, developing, motivating and retaining the best skilled personnel to man it.

- Knowledgeable, skilled and ethical financial and other resource managers: In several countries currently there is what may be called a crisis in the area of transparency, accountability, ethics, and integrity especially related to the management of financial resources.

- Knowledgeable and skilled information managers: Effective policy and strategy analysis, formulation, planning, monitoring, and evaluation strongly depend on systems, processes, and practices of information management that can avail timely, accurate, well organized, and accessible information.

- Public servants who cherish professionalism, ethics and integrity: While skills and knowledge are essential for performing any public service function, we must acknowledge that without appropriate values such as professionalism, ethics, integrity, the public service will remain under disdain. Inadequate integrity, unethical behavior and lack of professionalism breed and sustain corruption and other forms of malpractices that have characterized the public service in many African countries. Many projects and programmes aimed at improving service delivery and reducing poverty in many countries miss their targeted objectives because their resources are embezzled and diverted by officials who lack integrity.

- Public servants that are knowledgeable, skilled and committed in executing functions related to ensuring law and order, justice, audit and administrative control: Respecting laws, rules, regulations, and due procedures is a cardinal requirement for a well functioning public service system. It is the basis of the rule of law, democracy and fairness. However, its administration is not an automatic given; it requires dedicated and capable personnel.

- The need to anchor human capacity on sound, institutional and systemic capacity: However, human numbers, knowledge, skills, attitudes, networks and cherished values do not translate themselves into effective performance capacity unless they are operating within appropriate institutional, systemic, and structural frameworks. If the public service is not professionalized, it is not easy to attract professionals in it.

\subsection{The strategic human resource as a response to the challenge of globalization in Africa}

The strategic human resource management (SHRM) involves a set of internally consistent policies and practices designed and implemented to ensure that a firm's human capital (employees) contribute to the achievement of its business objectives has L. Baird, I. Meshoulam, (1998) J. E. Delery, D.H. Doty, (1996) M.A. Huselid, S .E. Jackson, R. S. Randall, (1997) S.E Jackson, R. S. Schuler,(1995)developed a more comprehensive academic definition of SHRM: Strategic human resources management is largely about integration and adaptation, its concern is to ensure that:

- Human resources management is fully integrated with the strategy and the strategic needs of the firm; 
- HR policies cohere both across policy areas and across hierarchies; and

- HR practices are adjusted, accepted, and used by line managers and employees as part of their everyday work.

P.M. Wright, G. C. Mcmahan, (1992) SHRM refers to "the pattern of planned human resource deployments and activities intended to enable an organization to achieve its goals". Hence, it appears that some of the frequently cited fundamental elements of SHRM in the literature are: SHRM practices are macro-oriented, proactive and long term focused in nature; views human resources as assets or investments not expenses; implementation of SHRM practices bears linkage to organizational performance; and focusing on the alignment of human resources with firm strategy as a means of gaining competitive advantage J.P. feffer, (1994) R. S. Schuler (1992).

\subsubsection{Improving efficiency, effectiveness, achieving better performance, equity, ethics and accountability}

The author start with the assumption that the most successful, efficient and effective public officials generally work at a low coefficient of performance as measured against their potential. One basic approach to enhance efficiency, effectiveness and accountability is to ask what minor and major changes are required of senior officials in terms of competencies, skills, behaviour, attitude, organizational structure, strategy, rules, regulations, processes, technology and other factors in order to improve or alter existing situations of low efficiency and effectiveness, poor performance, as well as ethics lapses leading to management deficit. Promoting efficiency, enhancing effectiveness and improving performance of senior officers cannot be a onetime exercise. The process requires unremitting efforts on a variety of fronts over a long continuous period of time.

\subsubsection{Causes of inefficiency/Poor performance}

The following are the main causes of inefficiency and poor performance.

i. Lack of clarity as to the mission and goals of governmental organizations. Gap between national and international demands of the 21st Century and outmoded capacity of senior officers to meet them.

ii. An over-centralized organizational structure, as well as rigid, often irrelevant, and unevenly enforced rules which result in delays in responding to clients, and distract senior officials from strategy formulation and policy-making.

iii. Faulty organizational structures and management processes.

iv. Decision making is centralized and there is a general failure to delegate.

Hierarchical management structures and failure to delegate authority are pervasive practices within the bureaucracy which hampers efficiency.

i. The system suffers from deteriorated professionalism and lacks professional orientation, thereby contributing to inefficiency and incompetent public image. 
ii. Poor personnel management is particularly relevant when flawed practices lead to low morale, giving rise to discontent, frustration, low wages and poor public image.

iii. Low level of skills and shortages in the delivery of public services is due to a variety of reasons such as progressively deteriorating educational standards, inadequate training and human resource development.

iv. Weak accountability mechanisms. While accountability to external institutions has been all along unsatisfactory in most developing countries, even the internal systems of accountability within the public services relying on instruments such as objective performance evaluation, merit based promotion processes and amenability to official discipline have been greatly weakened.

v. Poor incentives and compensation leading to low wages and frustration.

vi. An inappropriate skills mix, reflecting: (a) the past role of the state as employer of first resort and the associated expansion of employment at low skill levels and (b) the closed nature of the civil service, which imposes constraints on the government to introduce needed skills at higher grade levels from the market.

vii. Lack of proper output oriented job descriptions.

viii. In many cases, the general level of efficiency is deliberately kept low by the concerned officials because of corrupt motives.

If there is lack of efficiency, papers do not move quickly enough thereby affording opportunities to public officers to indulge in corrupt practices. In fact, the phenomenon of "speed money" is becoming more and more common. This malpractice was generally found earlier among lower officials. However, the malaise has been spreading upwards to senior echelons. The causes responsible for the unsatisfactory performance of the public sector can be tackled in the short term or in a medium term time horizon. Others would, e.g. improvement in education system, require efforts extending over a very long period of time.

\subsubsection{The efficiency and accountability improvement}

In this section, an attempt will be made to selectively focus on efficiency and accountability of senior officials in many developing countries reforms to address these issues has been initiated from time to time. Since 1947 one might even say that developing countries bureaucracy has been perpetually in a reform mode. There have been a number of commissions and committee assigned with the task of implementing reforms in order to improve the performance of public administration. However, none of the reports of these Commission and Committees could be fully implemented, essentially, due to lack of political will and entrenched vested interests. Few recommendations have been implemented; resulting in some improvement but far less than what is needed in a developing country facing the challenges of the 21st Century. The author step forward by arguing that different governments, politicians, army and senior public officials implemented those parts of reforms they liked and failed to implement the recommendation not suitable to their vested interests. 


\subsubsection{Human resource development and senior officials}

A clear paradigm shift is taking place as senior officials are increasingly committed to good governance and public management. The concept of governance is reshaping due to drivers of change-global interdependence, communication and information revolution and the rising expectations of the masses to be involved in the decisions of the government. Access to information, transparency of decisions can dramatically strengthen accountability, improve efficiency and effectiveness. Human Resource rejuvenation is the key to the renewal of public management. The Civil Services in general and senior officials in particular require a different set of skills to manage these turbulent times. Capacity building of senior public officials must become the top priority of governments that wish to achieve sound policy objectives in general and delivery of services in particular.

There is an overall shortage of training opportunities at all levels of hierarchy. The shortage is due to several reasons including the fact that training is often treated as a discrete event rather than part of an overall human resource development strategy. Competent trainers are in short supply and trainers get few opportunities to enhance their skills in "Training and updating knowledge". A big portion of the training curricula and material is based on borrowed and often outdated models. The classroom based lecture style training/teaching dominates most training programs. Most of the training material is theoretical whereas inter linkages with the actual work environment are less than desired. Training evaluation, impact assessment and monitoring of job performance are rarely measured. However for training of senior officials, Most of developing countries have made significant progress. This step is adding great value to the capacity of civil servants and helping them to bridge the gap between their capacities and competencies and requirements of the present times. In order to further strengthen training programmes so that they provide public officials with the necessary skills to meet many challenges of contemporary democracies.

\section{Conclusion and recommendation}

Globalization has its positive side as well as its negative side. It affects the economic dimensions; that is trade, finance, aid, migration and ideas. Increases in these dimensions of globalization, if managed in a way that supports development in all countries, can help alleviate global poverty under certain conditions. However as much as globalization is said to lead to job creation, the jobs created for African countries should strengthening human capacity in the public service, as a general subject is complex because countries, even in Africa are not homogenous. Even the public and the private sectors are rarely homogeneous. There are substantial differences even between categories of skills, calling for differential "strategies" for staffing for quality performance in the public service. First we need to underscore the primordial role the overall governance environment plays in attracting and retaining the best talent in the public service. Governors in all African countries need to be mindful of the relationship between the kind of governance they practice and the quality of the human resource they need. The umbrella strategy required concerns how to revamp the image of the public service. As long as the image continues to 
push the best employees out of the public service while at the same time repelling young graduates, efforts of staffing the service for excellent performance cannot be successful. The new public management criticism of "rules-bound" administration notwithstanding, it needs to be emphasized that long term strategies cannot be put into effect without a sound institutional framework. It is what lends credibility and decimation to particular actions and measures and thus dispels the impression of "politics as usual ". We need this credibility and legitimating not only to combat the presence or suspicion of clientelism and patronage, but also and most importantly, to enhance the image, prestige, and professional credentials of the public service. In practice the term "Staffing" encompasses every activity in human resource management. It includes forecasting human resource needs, planning, prospecting, attraction, selection, recruitment, deployment, human resource development including training, career management and motivation, performance evaluation, discipline, remuneration, promotion and separation. At the same time it also implies a necessary relationship and interdependence between all of the above. Therefore, there is a strong need for a holistic approach. Fragmented measures cannot yield the needed results. They merely lead to waste, in a large number of cases. This underscores the importance of the two critical factors for effective staffing for excellent performance in the public service. One is a long term strategy and the other is a credible and coherent institutional framework in terms of systems and structures, rules and regulations, procedures and processes, policies and programmes. This clearly points to the importance of each country, considering its specific situation, having an appropriate personnel system for managing human resources in the public service.

\section{Author details}

Philemon Kazimil Mzee

Transportation Management College,

Dalian Maritime University Dalian, China

\section{Acknowledgement}

The author would like to express appreciation to Prof. Yan Chen for guidance and Dr. Lili $\mathrm{Qu}$ for providing useful contact. This work was supported by specialized research fund for the doctoral programme of Higher Education (No 200801510001) and National Natural Science foundation of China (No. 70940008).

\section{References}

[1] R. A. Noe, J. R.Hollenbeck, B. Gerhart, P. M. Wright, "Human Resource Management: Gaining a Competitive Advantage", $3^{\text {rd }}$ Ed., Singapore: McGraw Hill, 2000.

[2] I. Goldin, K. Reinert, "Globalization for Development". New York: World Bank and Palgrave Macmillan, 2007. 
[3] United Nations Conference on Trade and Development Report, "E-commerce and Development Report". 2003, UNCTAD Secretariat: http:// www.unctad.org/ecommerce

[4] Organisation for Economic Cooperation and Development (OECD), "Trends in International Migration". Annual Report 2004 Edition, Paris, (2004b).

[5] Least Developed Countries Report. "Knowledge, Technological and Innovation for Development". United Nations Report, 2007.

[6] M.Brown, J. B.Meyer, Scientific Diasporas: A new approach to Brain Drain : Management of Social Transformations .OCLC 224980489, 1999.

[7] T. L. Weiss, “L 'Afrique a' la Poursuite de Ses Cerveaux. Jeune Afrique”. L' Intelligent 2104, 2001, pp. 8-14.

[8] UNAIDS: Turning a crisis into an opportunity: Strategies for Scaling up the National Response to the HIV/AIDS Pandemic in Lesotho. 2003 p 206

[9] Zuma: 2003 cited in IDASA UNDP 2003

[10] Kevin De Cock et al: 2002, The Lancet p. 67

[11] Andress 2002:4; Amsden 2003:33

[12] Ravenhill John. 2001

[13] Laszlo Ervin, Krtzman Joel and Bhattacharya AK. 1981. RCDC (regional cooperation among developing countries: the new imperative of development in the 1980s. New York: Pergamon Press. p 16

[14] NEPAD 2002. Annual report : towards Claiming the 21st century. p25

[15] Abdoulie Janneh 2001 How UNDP sees AIDS in Africa, in AIDS/AFRICA July/ August 2001 Issue 398 AIDS policy research center: 2002

[16] www.ilo.org/public

[17] L Baird, I. Meshoulam, "Managing the two fits of strategic human resource management", Academy of Management Review, 1988. 13, pp. 116- 28

[18] J. E Delery, D. H. Doty, "Modes of theorizing in strategic human resource management: Tests of universalistic, contingency and configurational performance predictions", Academy of Management Journal, 1996. Vol.39, no.4, pp. 802-835.

[19] M.A. Huselid, S.E Jackson, R.S.Randall, "Technical and strategic human resource management effectiveness as determinants of firm performance". Academy of Management Journal, 1997, vol.40, no.1, pp. 171 - 188

[20] S. E.Jackson, R. S. Schuler, “Understanding human resource management in the context of organizations and their environments". In M. R. Rosenszweig \& L.W. Porter (Eds.), Annual Review of Psychology, 1995. vol. 46, pp. 237 - 264. Palo alto, CA: Annual Reviews.

[21] R. S. Schuler, "Strategic human resource management: Linking people with the needs of the business". Organizational Dynamics, 1992, vol.21, no.1, pp. 18-32.

[22] P.M.Wright, G. C. McMahan, "Theoretical perspectives for strategic human resource management", Journal of Management, 1992. Vol.18, no.2, pp. 295 - 320

[23] J. Pfeffer, "Competitive Advantage through People: Unleashing the Power of the Workforce". Boston: Harvard Business School Press, 1994. 